\title{
Bioinformatics analyses on the immune status of renal transplant patients, a systemic research of renal transplantation
}

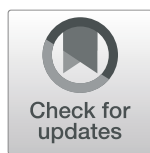

Mei Meng ${ }^{1,2+}$, Weitao Zhang ${ }^{1,3+}$, Qunye Tang ${ }^{1,3}$, Baixue $\mathrm{Yu}^{1,2}$, Tingting $\mathrm{Li}^{1,2}$, Ruiming Rong ${ }^{1,3}$, Tongyu Zhu ${ }^{1,3}$, Ming $\mathrm{Xu}^{1,3^{*}}$ and $\mathrm{Yi} \mathrm{Shi}^{1,2^{*}}$ (iD

\begin{abstract}
Background: Kidney transplantation is the most effective treatment for end-stage renal disease. Allograft rejections severely affect survivals of allograft kidneys and recipients.

Methods: Using bioinformatics approaches, the present study was designed to investigate immune status in renal transplant recipients. Fifteen datasets from Gene Expression Omnibus (GEO) were collected and analysed. Analysis of gene enrichment and protein-protein interactions were also used.

Results: There were 40 differentially expressed genes (DEGs) identified in chronic rejection group when compared with stable recipients, which were enriched in allograft rejection module. There were 135 DEGs identified in acute rejection patients, compared with stable recipients, in which most genes were enriched in allograft rejection and immune deficiency. There were 288 DEGs identified in stable recipients when compared to healthy subjects. Most genes were related to chemokine signalling pathway. In integrated comparisons, expressions of MHC molecules and immunoglobulins were increased in both acute and chronic rejection; expressions of LILRB and MAP 4 K1 were increased in acute rejection patients, but not in stable recipients. There were no overlapping DEGs in blood samples of transplant recipients.
\end{abstract}

Conclusion: By performing bioinformatics analysis on the immune status of kidney transplant patients, the present study reports several DEGs in the renal biopsy of transplant recipients, which are requested to be validated in clinical practice.

Keywords: Bioinformatics, Kidney transplantation, Immune regulation

\section{Introduction}

Kidney transplantation is the most effective treatment for end-stage renal disease. However, acute and chronic graft rejections affect survivals of allograft kidneys and transplant patients $[1,2]$. Acute rejection is characterised by a quick loss of renal function, whereas chronic rejection presents gradual development of renal failure. Pathological diagnosis is the best approach to assess disease classification and differentiate complications. However, many cases are diagnostically difficult since disease

\footnotetext{
* Correspondence: xu.ming@zs-hospital.sh.cn; shi.yi@zs-hospital.sh.cn ${ }^{\dagger}$ Mei Meng and Weitao Zhang contributed equally to this work.

'Shanghai Key Laboratory of Organ Transplantation, Shanghai, China

${ }^{2}$ Institute of Clinical Science, Zhongshan Hospital Fudan University, Fenglin Road 180, Shanghai PRC CN-200032, China

${ }^{3}$ Department of Urology, Zhongshan Hospital Fudan University, Fenglin Road 180, Shanghai PRC CN-200032, China
}

processes share nonspecific mechanisms, including innate immunity [3, 4], inflammation [5-7], and microcirculation remodelling [8].

Mechanisms and key regulators underlying the development of allograft rejection are complicated. Increased presences of major histocompatibility complex (MHC, also known as human leukocyte antigen HLA) are found in allografts, from both acute and chronic rejection patients, demonstrating that MHC upregulation is the crucial issue in the allograft immune responses. Meanwhile, the immune system from recipients targets foreign $\mathrm{MHC}$ proteins and triggers allograft immune responses. T lymphocytes take a significant part in the process of acute rejection, while B lymphocytes are more critical in the development of 
transplant tolerance and chronic rejection $[9,10]$. Thus, it is crucial to understand the immune status and the involvement of lymphocytes in transplant recipients.

In the last decade, gene microarray has been extensively used in transplant immunology [11]. Data from renal biopsies and liquid biopsies provide potential molecular signatures and precision assessments in the immune status of allograft recipients [12]. It is reported that upregulated genes in renal biopsies from acute rejection patients are involved in immune and inflammatory responses, whereas downregulated genes are more involved in different categories of cellular metabolism [13]. In recipients with stable kidney function, DEGs are classified into cell growth, protein metabolism as well as transcription factors, indicating subclinical immune responses [14]. Compared with stable recipients, acute rejection patients present complement activation and lower expressions of serpin family protein in plasma, indicating increased systemic inflammation and impaired vascular permeability [7]. In peripheral blood samples, increased type I interferon signaling represents a molecular signature in chronic antibody-mediated rejection [15]. Of note, underlying molecular regulations in inflammation and immune responses, both innate and adaptive response, are months before histologic lesions appear [16]. Thus, to better understand changes of immune state and underlying molecular regulation in transplant recipients, the present study recruited 15 datasets of renal transplant recipients from GEO. Analysis of gene enrichment and protein-protein interactions were also performed to identify potential regulators in the progress of allograft rejection.

\section{Method}

\section{Microarray datasets and groups}

There were 111 datasets regarding human kidney transplantation in the GEO database (http://www.ncbi.nlm. nih.gov/pubmed/GEO). The present study recruited 15 datasets of renal transplant patients with stable condition, acute rejection, chronic rejection or immune tolerance $[7,13,15-26]$. Studies involving acute kidney injury, pediatric transplantation, or different therapeutic regimes on immune response were excluded (Fig. 1, Additional file 1: Table S1). All 15 studies were carried out in North American [7, 13, 16, 18-21, 23-26] or Europe $[15,17,22]$. Most participants in the studies were Caucasian, while a few subjects were African-American, Asian or American Indian.

In the present study, five datasets were examined immune statuses of healthy subjects and stable recipients, two for renal biopsies [13, 17] and three for blood samples $[13,22,23]$. Ten studies were focused on acute rejection when compared with stable recipients, seven for renal biopsies [13, 16-21] and four for blood samples [7, $13,24,25]$. Six studies were pooled to study immune responses in chronic rejection when compared with stable recipients, three for renal biopsies $[17,19,20]$ and three for blood samples $[15,22]$. Also, there were three sets examined the immune status in transplant tolerant recipients, focusing on the gene signature of peripheral $\mathrm{B}$ lymphocytes [22, 23, 26] (Fig. 1, Tables 1 and 2).

There were no animal or human subjects involved in the present study.

\section{Data processing and analysis}

The 15 datasets were downloaded from the GEO database and analyzed separately. The preprocessing of the microarray dataset with raw data was performed by

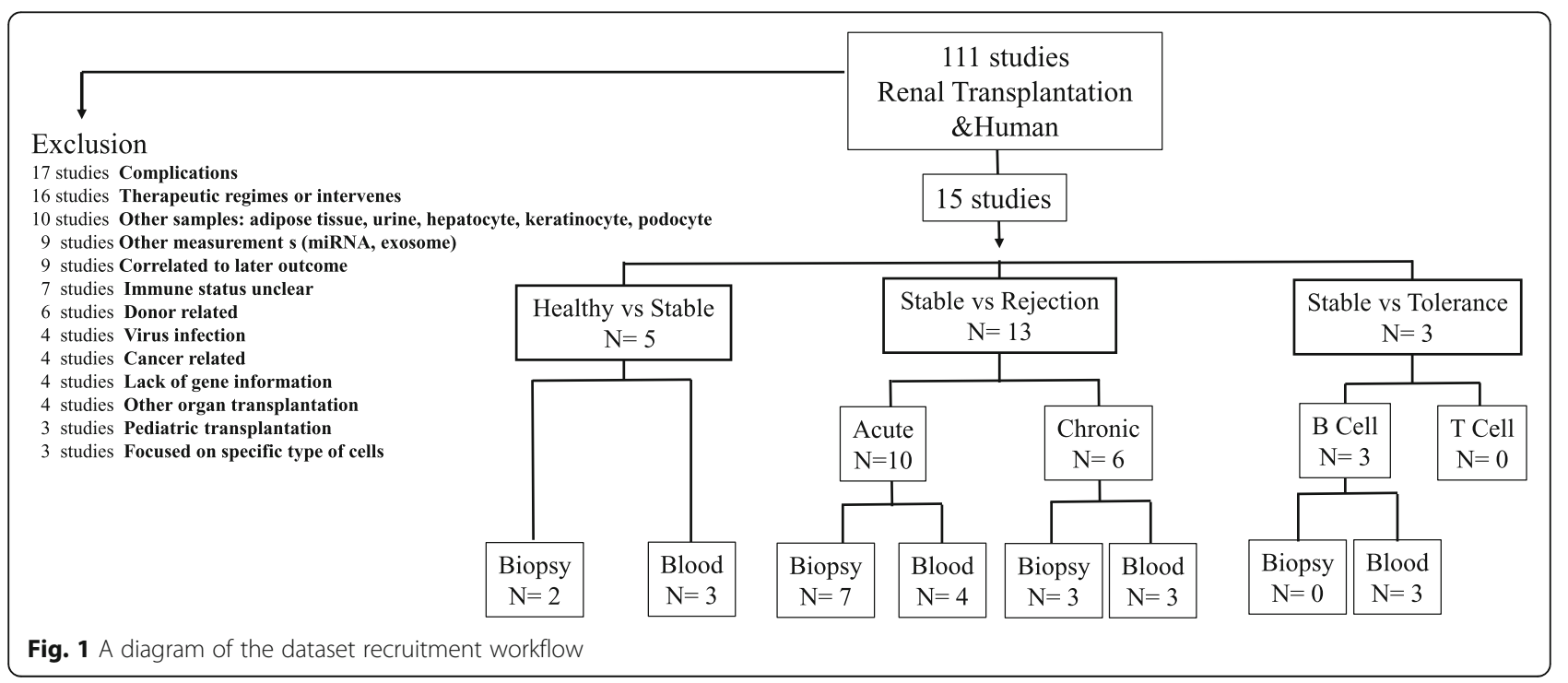


Table 1 GEO datasets of renal biopsies from kidney transplant recipients

\begin{tabular}{|c|c|c|c|c|c|}
\hline & Data Sets & Sample size & & Up-regulated & Down-regulated \\
\hline \multirow[t]{4}{*}{ Stable vs Healthy } & GSE9493 [17] & Stable & 21 & 1422 & 1742 \\
\hline & & Healthy & 15 & & \\
\hline & GSE1563 [13] & Stable & 10 & 1159 & 1149 \\
\hline & & Healthy & 9 & & \\
\hline \multirow[t]{14}{*}{ Acute vs Stable } & GSE9493 [17] & Acute & 10 & 3 & 3 \\
\hline & & Stable & 21 & & \\
\hline & GSE1563 [13] & Acute & 6 & 1178 & 1247 \\
\hline & & Stable & 9 & & \\
\hline & GSE50058 [18] & Acute & 43 & 1945 & 2328 \\
\hline & & Stable & 58 & & \\
\hline & GSE25902 [16] & Acute & 24 & 6964 & 6915 \\
\hline & & Stable & 96 & & \\
\hline & GSE36059 [19] & Acute & 35 & 1422 & 965 \\
\hline & & Stable & 281 & & \\
\hline & GSE98320 [20] & Acute & 81 & 1042 & 684 \\
\hline & & Stable & 774 & & \\
\hline & GSE106675 [21] & Acute & 10 & 2107 & 2022 \\
\hline & & Stable & 6 & & \\
\hline \multirow[t]{6}{*}{ Chronic vs Stable } & GSE9493 [17] & Chronic & 25 & 1377 & 1227 \\
\hline & & Stable & 21 & & \\
\hline & GSE36059 [19] & Chronic & 65 & 236 & 23 \\
\hline & & Stable & 281 & & \\
\hline & GSE98320 [20] & Chronic & 326 & 271 & 5 \\
\hline & & Stable & 774 & & \\
\hline
\end{tabular}

using the Affy package in the $\mathrm{R}$ environment (version 3.4.2, https://www.R-project.org). For background correction, normalization, and differentially expressed genes (DEGs) screening, limma and impute packages were used in the present study [27]. DEGs, both upregulated and downregulated, were defined when absolute log2 FC was higher than 0.5 and an adjusted $p$-value was less than 0.05 . To correct multiple hypotheses, BenjaminiHochberg false discovery rate correction was used to adjust $\mathrm{p}$-value in the present study. Annotation files for different microarray platforms are downloaded from the GEO database as well. STRING, an online tool, was used to explore protein-protein interactions [28]. ClueGO, a plug-in in Cytoscape 3.6.1, was used to group functional proteins and visualise their biological terms [29].

The overlapping genes in integrated comparisons were visualised by using the Venn package in R. Changes of genes in the intersection were normalised with the controls in the same dataset, and presented as fold changes. The statistical analysis between two groups was done by two-tailed student $\mathrm{t}$-test. Differences were considered to be statistically significant when $p$-value was less than 0.05 .

\section{Results}

Gene profiling of renal biopsies from transplant recipients Chronic rejection vs stable recipients

Three datasets were comparing renal biopsies of chronic rejection patients with stable recipients. A total of 40 DEGs were found in chronic rejection patients (Fig. 2a). All the genes were enriched in the allograft rejection module (Fig. 2b and $2 \mathrm{c}$ ).

\section{Acute rejection vs stable recipients}

Seven datasets were comparing renal biopsies from acute rejection patients with stable subjects. After removing GSE9493 since only six DEGs were found, a total of 135 DEGs were found in common (Fig. 3a). ClueGO showed that $58.4 \%$ of genes were enriched in allograft rejection module, $12.2 \%$ in the chemokine signalling pathway module, and $9.76 \%$ in primary immunodeficiency module. Other modules included nuclear factor kappa B (NF-kB) signalling pathway, Toll-like receptor (TLR) signalling, and peroxisome proliferator-activated receptors signalling pathway (Fig. $3 \mathrm{~b}$ and $3 \mathrm{c}$ ). 
Table 2 GEO datasets of blood samples from kidney transplant recipients

\begin{tabular}{|c|c|c|c|c|c|}
\hline & Data Sets & Sample Size & & Up-regulated & Down-regulated \\
\hline \multirow[t]{6}{*}{ Stable vs Healthy } & GSE1563 [13] & Stable & 9 & 915 & 947 \\
\hline & & Healthy & 8 & & \\
\hline & GSE47755 [22] & Stable & 380 & 26 & 8 \\
\hline & & Healthy & 16 & & \\
\hline & GSE22229 [23] & Stable & 27 & 173 & 295 \\
\hline & & Healthy & 12 & & \\
\hline \multirow[t]{8}{*}{ Acute vs Stable } & GSE1563 [13] & Acute & 6 & 49 & 57 \\
\hline & & Stable & 9 & & \\
\hline & GSE14346 [24] & Acute & 38 & 1015 & 1563 \\
\hline & & Stable & 37 & & \\
\hline & GSE15296 [25] & Acute & 51 & 591 & 707 \\
\hline & & Stable & 24 & & \\
\hline & GSE46474 [7] & Acute & 20 & 15 & 4 \\
\hline & & Stable & 20 & & \\
\hline \multirow[t]{6}{*}{ Chronic vs Stable } & GSE47755 [22] & Chronic & 78 & 2 & 0 \\
\hline & & Stable & 380 & & \\
\hline & GSE51675 [15] & Chronic & 10 & 2 & 0 \\
\hline & & Stable & 8 & & \\
\hline & GSE64261 [15] & Chronic & 5 & 0 & 0 \\
\hline & & Stable & 5 & & \\
\hline \multirow[t]{6}{*}{ Tolerance vs Stable } & GSE47755 [22] & Tolerance & 54 & 1 & 3 \\
\hline & & Stable & 380 & & \\
\hline & GSE22229 [23] & Tolerance & 19 & 72 & 8 \\
\hline & & Stable & 27 & & \\
\hline & GSE66612 [26] & Tolerance & 81 & 51 & 61 \\
\hline & & Stable & 77 & & \\
\hline
\end{tabular}

\section{Stable vs healthy subjects}

Two datasets were comparing renal biopsies of healthy subjects and stable recipients. A total of 288 DEGs were found in stable recipients compared with healthy subjects (Fig. 4a). ClueGO showed that $61.7 \%$ of genes were enriched in chemokine signalling pathway module; other modules included prion diseases, TLR signalling, endometrial cancer, long-term potentiation, and shigellosis. (Fig. 4b and c).

\section{Progressive changes in integrated comparisons}

To understand changes of immune status in transplant patients, DEGs identified above were further analysed in combined comparisons (Fig. 5a).

There were three DEGs found in both stable and chronic rejection groups. Immunoglobulin heavy constant $\mathrm{Mu}(I G H M)$, immunoglobulin heavy variable 4-31 (IGHV4-31), and immunoglobulin heavy constant gamma of 1 (IGHG1) were upregulated in chronic rejection patients, but not in stable recipients. (Fig. 5 B, Additional file 1: Table S2).

There were 10 DEGs found in both stable and acute rejection groups. Among them, albumin $(A L B)$ and cytochrome P450 3A4 (CYP3A4) were downregulated, while cluster of differentiation $48(C D 48)$, protein tyrosine phosphatase receptor type $\mathrm{C}(P T P R C$, also known as $C D 45)$, adenosine deaminase $(A D A)$, and formin binding protein 1 (FNBP1), ecotropic viral integration site $2 \mathrm{~B}$ $(E V I 2 B)$ were upregulated. Expressions of mitogenactivated protein kinase kinase kinase kinase 1 (MAP 4 K1), leukocyte immunoglobulin-like receptor B2 (LILRB2), and IGHG1 were increased in acute rejection patients, but not in stable transplant recipients (Fig. 5c, Additional file 1: Table S3).

There were 16 upregulated genes found in both acute and chronic rejection comparisons, including major histocompatibility complex class I (HLA-F) and II (HLADPA1, DPB1, HLA-DRA, DRB1, and DRB4), IGHG1, Fc fragment of IgG receptor IIIb (FCGR3B, also known as 


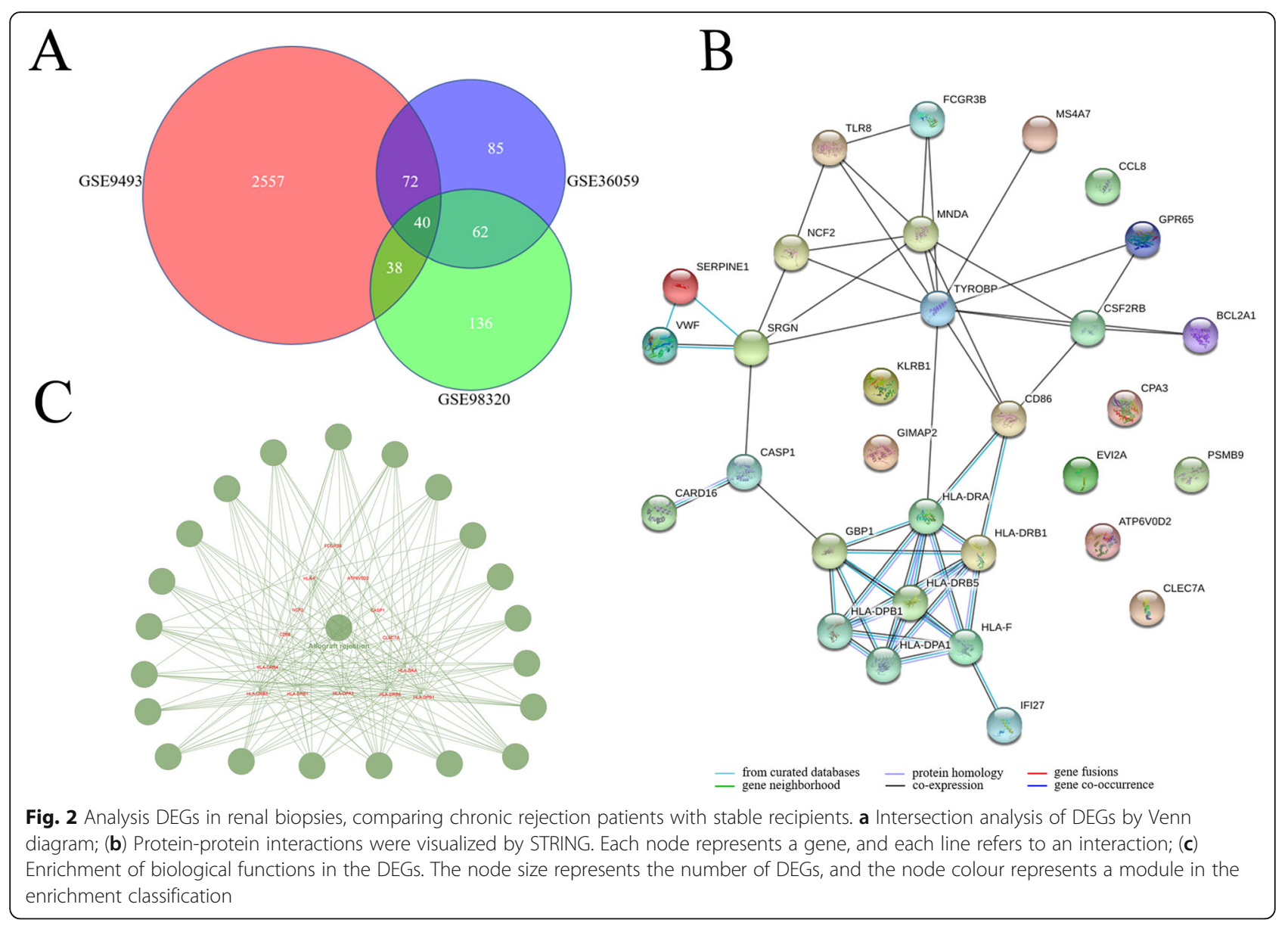

$C D 16 b), C D 86$, proteasome subunit beta 9 (PSMB9), guanylate binding protein 1(GBP1), serglycin (SRGN), neutrophil cytosolic factor 2 (NCF2), G protein-coupled receptor 65 (GPR65), caspase 1 (CASP1), and TYRO protein tyrosine kinase binding protein (TYROBP).

Of note, expressions of HLA-DPA1, DPB1, DRB4, CD86, GPR65, CASP1, TYROBP, and SRGN were significantly higher in the acute rejection group than those in the chronic one (Fig. 5d, Additional file 1: Table S4).

\section{Gene profiling of peripheral blood lymphocytes from kidney transplant recipients}

Likewise, comparisons of blood samples of transplant recipients were performed. There were no DEGs overlapped in combined comparisons (Fig. 6a-d).

\section{Discussion}

The present study performed systematic research on immune status in renal transplant recipients. Using bioinformatics approaches, molecular patterns were analysed in renal biopsies and peripheral blood lymphocytes of transplant recipients. The main findings include A) Upregulation of $\mathrm{MHC}$ presences is critical in initiating immune responses in both acute and chronic rejection. B) Increased expressions of LILRB and MAP $4 K 1$ are potential checkpoints for the occurrence of acute rejection. C) Gene profiles of peripheral blood lymphocytes are not in line with those of renal biopsies.

Increased expressions of $M H C$ molecules were found in both acute and chronic rejection, confirming the critical role of $\mathrm{MHC}$ in allograft immune responses. $\mathrm{MHC}$ II proteins, including HLA-DRA, -DPA, -DPB, -DQA and $\mathrm{DQB}$, confer heterodimeric protein receptors in cell membrane. Allograft recipients with donor-specific HLA-DP antibodies before the surgery suffer much severer antibody-mediated rejections than those without [30, 31]. PSMB9 is known as $20 \mathrm{~S}$ proteasome subunit beta-1i. When cells challenged with interferon-gamma, PSMB9 constitutes immunoproteasome to process MHC I molecules [32, 33]. The upregulation of PSMB9 has been reported in zero-hour [34, 35] and 6-month [36] renal biopsies as a potential candidate to predict acute and chronic graft nephropathy. CD86 offers costimulatory signals for $\mathrm{T}$ cell activation. The upregulation of CD86, together with the increased expressions of HLA primed the recruitment of $\mathrm{T}$ lymphocytes, revealing a 


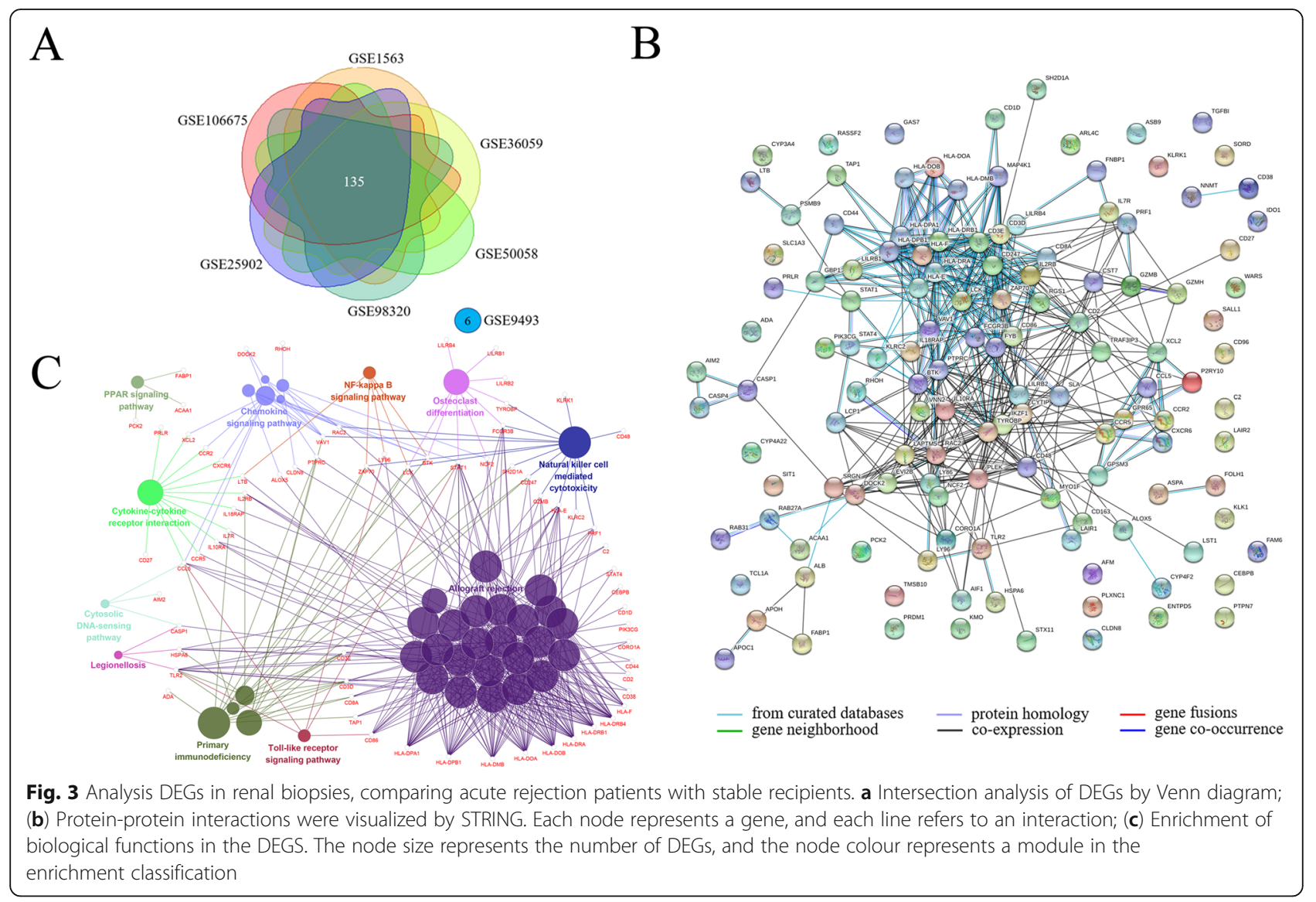

fundamental mechanism of allograft rejections. Furthermore, gene expressions of HLA-DPA1, DPB1, DRB4, and $C D 86$ were higher in the acute rejection than those in the chronic rejection, indicating that acute rejection induces stronger allograft immune responses.

Besides CD86 which is essential for $\mathrm{T}$ cell activation, other cell surface molecules were also identified in renal biopsies. Both CD45 (also known as PTPRC) and CD48 expressions are upregulated in rejection patients [37]. CD45 is the common leukocyte antigen, which is critical in regulating $\mathrm{T}$ - and $\mathrm{B}$-cell antigen receptor signalling. CD48 is a member of the lymphocyte activation signalling family. By interacting with other ligands, CD48 participates in graft rejection [38]. Combined treatment of anti-CD2 and -CD48 in vivo significantly improves mouse cardiac allograft survival, while administration of either antibody alone has little effects [39]. Combined therapy of anti-CD48, anti-lymphocyte functionassociated antigen 1 and fingolimod (a sphingosine 1phosphate receptor modulator for multiple sclerosis treatment) keeps embryonic pig pancreas function in diabetic mice [40]. CD16 is required for antibodydependent cell-mediated cytotoxicity processes in human monocytes [41].
Of note, IGHG1 was the only DEG found in all the renal biopsies, which was upregulated in both acute and chronic rejection patients but downregulated in stable recipients. Together with the other two genes encoding immunoglobulin heavy chains, IGHV4-31 and IGHM, it indicates that $\mathrm{B}$ lymphocytes are activated and differentiated when challenged with antigen in the progress of rejection $[23,42]$.

Taken together with the above gene-expression signature which belongs to B lymphocytes, $\mathrm{T}$ lymphocytes, and monocytes, it indicates that complex immune responses take place in the donor immune system. Considering their unique role of each immune cell in the enormous immune family, it is not always easy to differentiate acute rejection from chronic one, especially when acute rejection occurs simultaneously with the latter one.

MAP $4 K 1$ and LILRB2 were the two genes upregulated in acute rejection, but not in stable transplant recipients. The data suggest that MAP $4 \mathrm{~K} 1$ and LILRB2 probably are the potential checkpoint for the occurrence of acute rejection. MAP $4 \mathrm{~K} 1$ plays a role in the activation of c-Jun $\mathrm{N}$-terminal kinase, which contributes importantly to inflammatory responses in mammals [43]. 


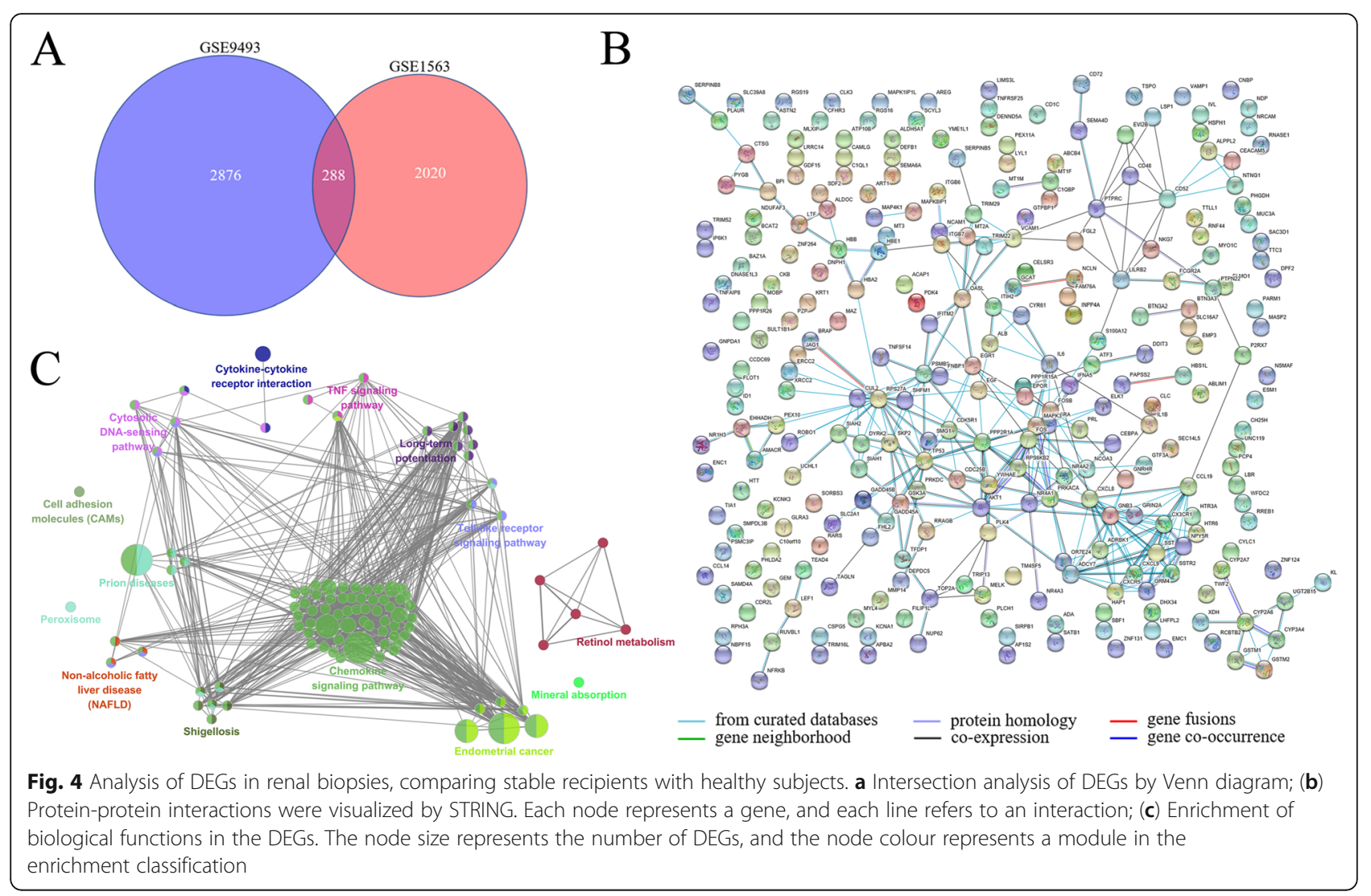

LILRB2 is extensively expressed on immune cells, such as natural killer cells, CD8+ T cells and B cells $[44,45]$. By recognising MHC I, LILRB2 prevents lymphocytes from killing MHC I-expressing cells [46]. The increased expression of LILRB2 indicates an enhanced immune response in acute rejection. However, it is also reported that cytomegaloviruses infection induces spontaneous mutation in MHC I protein and affects the interactions of MHC and LILRB2, suggesting an underlying mechanism of immune escape [14, 47].

In the present study, most DEGs in acute and chronic rejection profiles were enriched in immune responses such as allograft rejection and immune deficiency, implying that the balance between immune defence and attack play a critical role in transplant immunology. Nevertheless, most DEGs from stable recipients were enriched in inflammation, such as chemokine signalling, toll-like receptor signalling, cytokine-cytokine receptor interaction, natural killer cell-mediated cytotoxicity, NF$\kappa \mathrm{B}$ signalling pathway, indicating that inflammationrelated-signalling pathways play a role undermining the immune balance [48]. Upregulation of NCF2 in renal biopsies indicates that enhanced oxidative stress is an essential mechanism. Through cleavage by Casp1, interleukin-1 and -18 are secreted from the cell to induce the inflammatory response in neighbouring cells, [49] resulting in intense inflammatory, immune responses and acute rejection [3]. Increased expression of GBP1 is also reported in chronic rejection patients when compared with recipients with stable renal function [15]; however, the involvement of GBP1 in immune responses has not been studied.

$A L B$ and CYP3A4 were the two downregulated genes in the combined comparison of acute rejection groups and stable groups. In clinical research, serum albumin levels are negatively correlated with the outcome of allograft kidney and transplant patients [50-52]. Immunosuppressive agents, including tacrolimus and cyclosporine A, are inactive while bound with proteins. Increased serum concentrations of unbound medicine enhance the efficacy and toxicity of the medication [53]. On the other hand, these immunosuppressive agents cause a reduced synthesis and secretion of albumin in cultured human hepatocytes [54]. Most immunosuppressive medicine, including tacrolimus and cyclosporine A, are substrates of cytochrome P450, [55] but also have inhibitory effects on the enzyme [56]. Cytochrome $\mathrm{P} 450$ polymorphisms CYP3A4 in people are extremely high, [57] affecting medicine metabolism and efficacy [58-60]. 


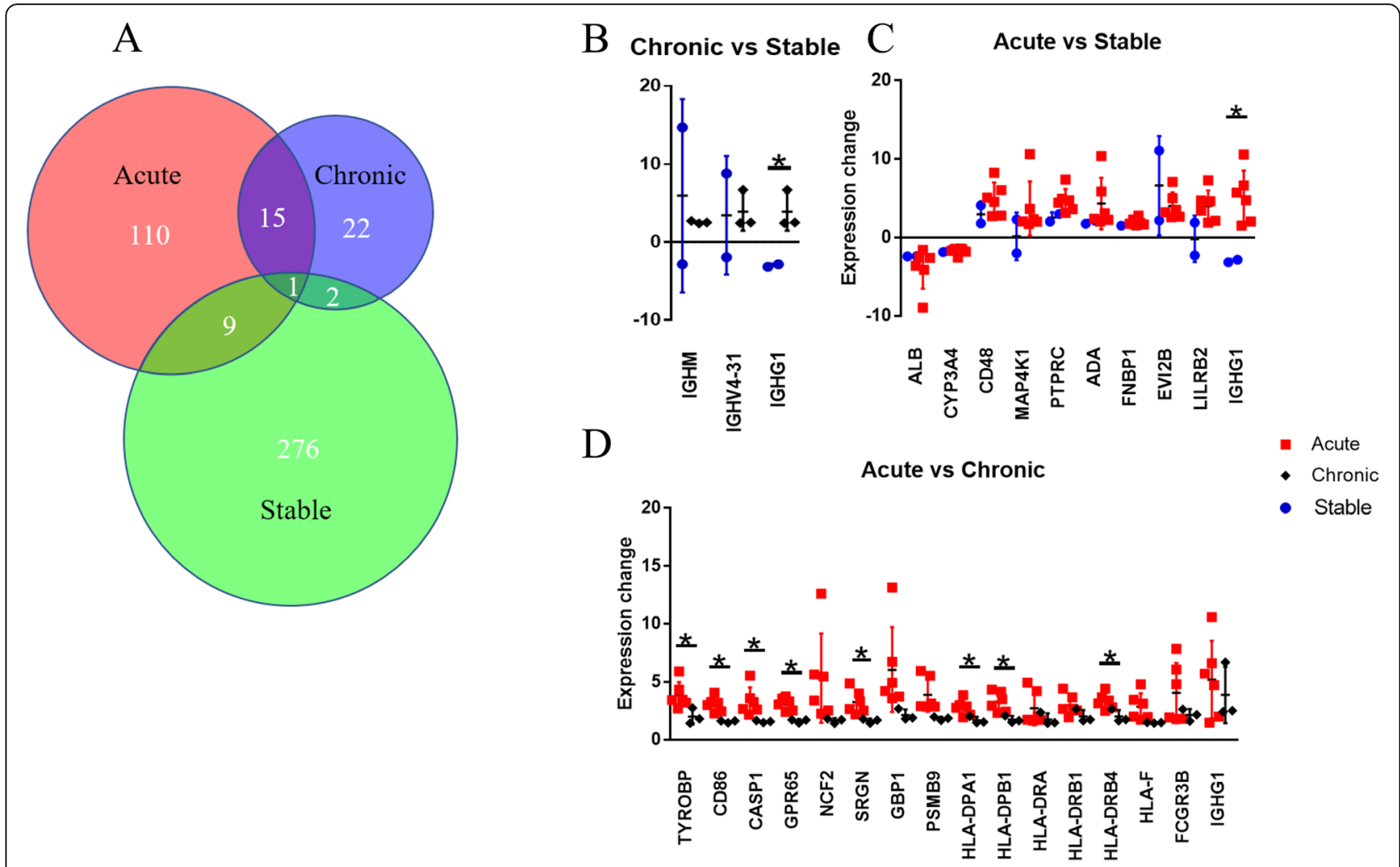

Fig. 5 a Integrated analysis of DEGs from renal biopsies of stable, acute rejection and chronic rejection groups. $\mathbf{b}$ Scatter plots of three DEGs identified in the comparison of chronic rejection patients and stable recipients. Gene changes are normalised with controls in the same dataset and presented as fold changes individually. Data are shown as means \pm standard error of the mean; 3 sets of chronic rejection and 2 sets of stable groups. c Scatter plots of 10 DEGs identified in the comparison of stable and acute rejection patients. Gene changes are normalised with controls in the same dataset and presented as fold changes individually. Data are shown as means \pm standard error of the mean; 2 sets of stable subjects and 6 set of acute rejection. $\mathbf{d}$ Scatter plots of 16 DEGs identified in the combined comparison of acute rejection and chronic rejection group. Gene changes are normalised with controls in the same dataset and presented as fold changes individually. Data are shown as means \pm standard error of the mean; 6 sets of acute rejection and 3 sets of chronic rejection. ${ }^{*} P<0.05$ vs acute rejection group

Other DEGs in the present study, including TYROBP, $A D A, E V I 2 B$, FNBP1, as well as GPR65, have not been thoroughly investigated in inflammation or transplant immunology.

Compared with conventional allograft biopsies, a blood draw of liquid biopsies is less invasive and easier handling [61]. There are several studies profiling renal biopsies and blood biopsies in parallel to monitor dynamic immune changes in transplant patients [13, 37]. Of note, only handful genes are consistently expressed in both peripheral blood and renal biopsies [13, 37], indicating that gene expression profiles of blood are distinctive from those of the biopsies of transplant patients [13]. By combining five public datasets of stable recipients and acute rejection patients, HIST1H4A coding basic nuclear protein histone $\mathrm{H} 4$ was the only candidate gene upregulated in both peripheral blood samples and renal biopsy [37]. It is reported that the B cell signature genes including IGKV4-1, IGLL1, and IGKVID-13 are upregulated in tolerant recipients when compared with transplant recipients with stable renal function [23]. However, the upregulation of IGKV4-1, IGLL1 or $I G K V 1 D-13$ is not reproduced in immune tolerance subjects who were treated with a bioengineered stem cell product [21]. Since no overlapping genes in peripheral blood were identified, there are several interpretations for the inconsistency 1) The activation and recruitment of peripheral blood cells and the subset of lymphocytes to the transplanted kidney are different, regarding sources and underlying mechanisms [13]. 2) The peripheral blood samples are affected by many other factors, including lifestyles, diets, and systemic disease as well as its corresponding therapeutic medicines. 3) Isolation of peripheral blood cells by density gradient purification can activate cells and induce gene changes ex vivo. Thus, it should be cautious of drawing a conclusion on immune status regarding changes in blood samples of transplant recipients. 


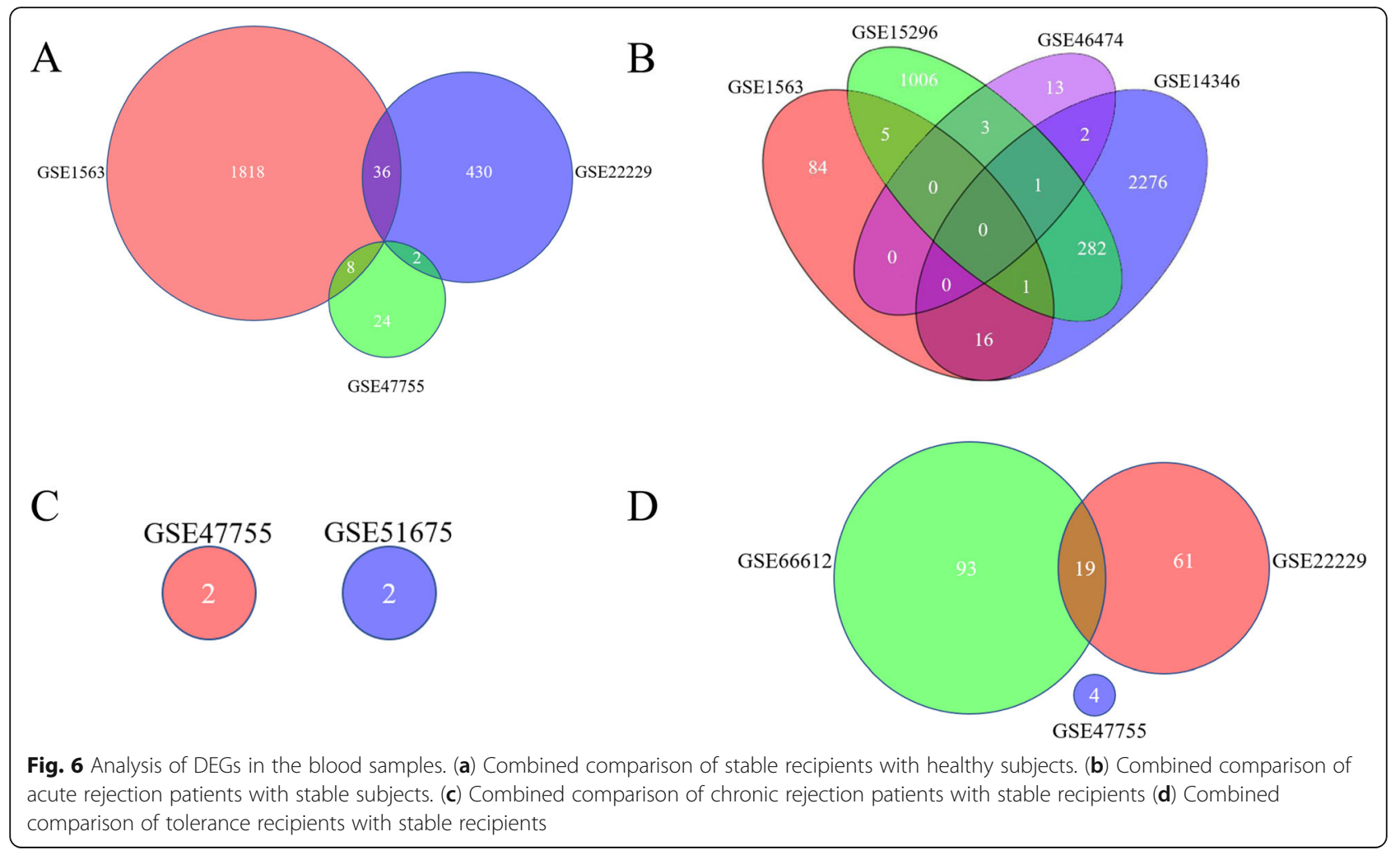

\section{Conclusion}

Due to the complexity of the immune system, maintaining the balance in immunosuppression, allograft organ rejection, and secondary infection is the ultimate goal for clinicians and organ transplant recipients. By performing bioinformatics analyses on the immune status of renal transplant patients, the present study reports several DEGs in the renal biopsy of transplant recipients, which will be validated in clinical practice.

\section{Supplementary information}

Supplementary information accompanies this paper at https://doi.org/10. 1186/s12920-020-0673-6.

Additional file 1: Table S1. GSE datasets of renal transplant patients. Table S2. The overlapping DEGs in the comparison of stable and chronic rejection groups. Table S3. The overlapping DEGs in the comparison of acute rejection and stable groups. Table S4. The overlapping DEGs in the comparison of acute rejection and chronic rejection groups

\section{Abbreviations}

ADA: Adenosine deaminase; ALB: Albumin; CASP1: Caspase 1; CD: Cluster of differentiation; CYP3A4: Cytochrome P450 3A4; DAP12: DNAX-Activation Protein 12; DEGs: Differentially expressed genes; EVI2B: Ecotropic viral integration site 2B; FCGR3B: Fc Fragment of IgG receptor IIIb; FNBP1: Formin binding protein 1; GBP1: Guanylate binding protein 1,; GEO: Gene Expression Omnibus; GPR65: G protein-coupled receptor 65; HIST1H4A: Histone cluster 1 H4 family member A; HLA: Human leukocyte antigen;

IGHG1: Immunoglobulin heavy constant gamma of 1

IGHM: Immunoglobulin heavy constant Mu; IGHV4--31: Immunoglobulin heavy variable 4--31; IGKV1D-13: Immunoglobulin kappa variable 1D-13; IGKV4--1: Immunoglobulin kappa variable 4--1; IGLL1: Immunoglobulin lambda like polypeptide 1; LILRB: Leukocyte immunoglobulin-like receptor B; LILRB2: Leukocyte immunoglobulin-like receptor B2; MAP 4 K1: Mitogenactivated protein kinase kinase kinase kinase 1; MAPK: Mitogen-activated protein kinase; MHC: Major histocompatibility complex; NCF2: Neutrophil cytosolic factor 2; NF-kB: Nuclear factor kappa B; PSMB9: Proteasome subunit beta type-9; PTPRC: Protein tyrosine phosphatase receptor type $C_{\text {; }}$

SRGN: Serglycin; TLR: Toll-like receptor; TYROBP: TYRO protein tyrosine kinasebinding protein

\section{Acknowledgments}

Not Applicable

\section{Authors' contributions}

MM, WZ, QT, BY, TL collected the data and performed analysis; RR provided technical assistance on data analysis; MM, WZ, MX and YS wrote the manuscript; $T Z, M X$ and $Y S$ designed the experiments, and $M X$ and $Y S$ gave final content approval; all authors read and edited/revised the manuscript.

\section{Funding}

This work was supported by the National Nature Science Foundation of China (No 81573418) and Zhongshan Hospital Seed Funding (ZSYXGG-014). The funding bodies played no role in the design of the study and collection, analysis, and interpretation of data and in writing the manuscript.

\section{Availability of data and materials}

GEO datasets recruited in the present study were available on Pubmed/GEO datasets repository. Detailed information listed in the supplemental file (S. Table 1).

Ethics approval and consent to participate Not Applicable.

\section{Consent for publication}

Not Applicable.

\section{Competing interests}

The authors declare no conflicts of interest. 


\section{Received: 8 May 2019 Accepted: 27 January 2020}

\section{Published online: 11 February 2020}

\section{References}

1. Petra $\mathrm{H}$, Eva $\mathrm{H}$, Irena $\mathrm{B}$, Petra $\mathrm{H}$, Ondrej V. Molecular profiling of acute and chronic rejections of renal allografts. Clin Dev Immunol. 2013;2013:509259.

2. Dennis MJ, Foster MC, Ryan JJ, Burden RP, Morgan AG, Blamey RW. The increasing importance of chronic rejection as a cause of renal allograft failure. Transpl Int. 1989;2(4):214-7.

3. Mueller FB, Yang H, Lubetzky M, Verma A, Lee JR, Dadhania DM, Xiang JZ, Salvatore SP, Seshan SV, Sharma VK, et al. Landscape of innate immune system transcriptome and acute T cell-mediated rejection of human kidney allografts. JCl Insight. 2019:4(13).

4. Wang YH, Zhang YG. Kidney and innate immunity. Immunol Lett. 2017; 183:73-8.

5. Carron C, Pais de Barros JP, Gaiffe E, Deckert V, Adda-Rezig H, Roubiou C, Laheurte C, Masson D, Simula-Faivre D, Louvat P et al: End-Stage Renal Disease-Associated Gut Bacterial Translocation: Evolution and Impact on Chronic Inflammation and Acute Rejection After Renal Transplantation Front Immunol 2019, 10:1630.

6. Carrero JJ, Stenvinkel P. Persistent inflammation as a catalyst for other risk factors in chronic kidney disease: a hypothesis proposal. Clin J Am Soc Nephrol. 2009;4(Suppl 1):S49-55.

7. Gunther OP, Shin H, Ng RT, McMaster WR, McManus BM, Keown PA, Tebbutt SJ, Le Cao KA. Novel multivariate methods for integration of genomics and proteomics data: applications in a kidney transplant rejection study. OMICS. 2014;18(11):682-95.

8. Rodder S, Scherer A, Raulf F, Berthier CC, Hertig A, Couzi L, Durrbach A, Rondeau E, Marti HP. Renal allografts with IF/TA display distinct expression profiles of metzincins and related genes. Am J Transplant. 2009;9(3):517-26.

9. Lechler Rl, Garden OA, Turka LA. The complementary roles of deletion and regulation in transplantation tolerance. Nat Rev Immunol. 2003;3(2): 147-58.

10. Zeng Q, Ng YH, Singh T, Jiang K, Sheriff KA, Ippolito R, Zahalka S, Li Q, Randhawa P, Hoffman RA, et al. B cells mediate chronic allograft rejection independently of antibody production. J Clin Invest. 2014; 124(3):1052-6.

11. Stegall M, Park W, Kim D, Kremers W. Gene expression during acute allograft rejection: novel statistical analysis of microarray data. Am J Transplant. 2002; 2(10):913-25.

12. Lin $Z$, Lin $Y$. Identification of potential crucial genes associated with steroidinduced necrosis of femoral head based on gene expression profile. Gene. 2017:627:322-6

13. Flechner SM, Kurian SM, Head SR, Sharp SM, Whisenant TC, Zhang J, Chismar JD, Horvath S, Mondala T, Gilmartin T, et al. Kidney transplant rejection and tissue injury by gene profiling of biopsies and peripheral blood lymphocytes. Am J Transplant. 2004;4(9):1475-89.

14. Mocarski ES Jr. Immune escape and exploitation strategies of cytomegaloviruses: impact on and imitation of the major histocompatibility system. Cell Microbiol. 2004;6(8):707-17.

15. Rascio F, Pontrelli P, Accetturo M, Oranger A, Gigante M, Castellano G, Gigante M, Zito A, Zaza G, Lupo A, et al. A type I interferon signature characterizes chronic antibody-mediated rejection in kidney transplantation. J Pathol. 2015;237(1):72-84.

16. Naesens M, Khatri P, Li L, Sigdel TK, Vitalone MJ, Chen R, Butte AJ, Salvatierra $\mathrm{O}$, Sarwal MM. Progressive histological damage in renal allografts is associated with expression of innate and adaptive immunity genes. Kidney Int 2011:80(12):1364-76.

17. Saint-Mezard P, Berthier CC, Zhang H, Hertig A, Kaiser S, Schumacher M, Wieczorek G, Bigaud M, Kehren J, Rondeau E, et al. Analysis of independent microarray datasets of renal biopsies identifies a robust transcript signature of acute allograft rejection. Transpl Int. 2009;22(3):293-302.

18. Khatri P, Roedder S, Kimura N, De Vusser K, Morgan AA, Gong Y, Fischbein MP, Robbins RC, Naesens M, Butte AJ, et al. A common rejection module (CRM) for acute rejection across multiple organs identifies novel therapeutics for organ transplantation. J Exp Med. 2013; 210(11):2205-21.

19. Reeve J, Sellares J, Mengel M, Sis B, Skene A, Hidalgo L, de Freitas DG, Famulski KS, Halloran PF. Molecular diagnosis of T cell-mediated rejection in human kidney transplant biopsies. Am J Transplant. 2013;13(3):645-55.
20. Reeve J, Bohmig GA, Eskandary F, Einecke G, Lefaucheur C, Loupy A, Halloran PF, group MM-Ks: Assessing rejection-related disease in kidney transplant biopsies based on archetypal analysis of molecular phenotypes. JCl Insight 2017, 2(12).

21. Gallon L, Mathew JM, Bontha SV, Dumur Cl, Dalal P, Nadimpalli L, Maluf DG, Shetty AA, Ildstad ST, Leventhal JR, et al. Intragraft molecular pathways associated with tolerance induction in renal transplantation. J Am Soc Nephrol. 2018;29(2):423-33.

22. Braud C, Baeten D, Giral M, Pallier A, Ashton-Chess J, Braudeau C, Chevalier C, Lebars A, Leger J, Moreau A, et al. Immunosuppressive drug-free operational immune tolerance in human kidney transplant recipients: part I. blood gene expression statistical analysis. J Cell Biochem. 2008;103(6):1681-92

23. Newell KA, Asare A, Kirk AD, Gisler TD, Bourcier K, Suthanthiran M, Burlingham WJ, Marks WH, Sanz I, Lechler Rl, et al. Identification of a B cell signature associated with renal transplant tolerance in humans. J Clin Invest. 2010;120(6):1836-47.

24. Li L, Khatri P, Sigdel TK, Tran T, Ying L, Vitalone MJ, Chen A, Hsieh S, Dai H, Zhang $\mathrm{M}$, et al. A peripheral blood diagnostic test for acute rejection in renal transplantation. Am J Transplant. 2012;12(10):2710-8.

25. Kurian SM, Williams AN, Gelbart T, Campbell D, Mondala TS, Head SR, Horvath S, Gaber L, Thompson R, Whisenant T, et al. Molecular classifiers for acute kidney transplant rejection in peripheral blood by whole genome gene expression profiling. Am J Transplant. 2014;14(5):1164-72.

26. Newell KA, Asare A, Sanz I, Wei C, Rosenberg A, Gao Z, Kanaparthi S, Asare S, Lim N, Stahly M, et al. Longitudinal studies of a B cell-derived signature of tolerance in renal transplant recipients. Am J Transplant. 2015;15(11):2908-20.

27. Irizarry RA, Bolstad BM, Collin F, Cope LM, Hobbs B, Speed TP. Summaries of Affymetrix GeneChip probe level data. Nucleic Acids Res. 2003;31(4):e15.

28. Szklarczyk D, Gable AL, Lyon D, Junge A, Wyder S, Huerta-Cepas J, Simonovic M, Doncheva NT, Morris JH, Bork P, et al. STRING v11: proteinprotein association networks with increased coverage, supporting functional discovery in genome-wide experimental datasets. Nucleic Acids Res. 2019; 47(D1):D607-13.

29. Bindea G, Mlecnik B, Hackl H, Charoentong P, Tosolini M, Kirilovsky A, Fridman WH, Pages F, Trajanoski Z, Galon J. ClueGO: a Cytoscape plug-in to decipher functionally grouped gene ontology and pathway annotation networks. Bioinformatics. 2009;25(8):1091-3.

30. Jolly EC, Key T, Rasheed H, Morgan H, Butler A, Pritchard N, Taylor CJ, Clatworthy MR. Preformed donor HLA-DP-specific antibodies mediate acute and chronic antibody-mediated rejection following renal transplantation. Am J Transplant. 2012;12(10):2845-8.

31. Hormann M, Dieplinger G, Rebellato LM, Briley KP, Bolin P, Morgan C, Haisch CE, Everly MJ. Incidence and impact of anti-HLA-DP antibodies in renal transplantation. Clin Transpl. 2016;30(9):1108-14.

32. Basler M, Kirk CJ, Groettrup M. The immunoproteasome in antigen processing and other immunological functions. Curr Opin Immunol. 2013; 25(1):74-80.

33. McConnell SC, Hernandez KM, Wcisel DJ, Kettleborough RN, Stemple DL, Yoder JA, Andrade J, de Jong JL. Alternative haplotypes of antigen processing genes in zebrafish diverged early in vertebrate evolution. Proc Natl Acad Sci U S A. 2016;113(34):E5014-23.

34. Kotsch K, Kunert K, Merk V, Reutzel-Selke A, Pascher A, Fritzsche F, Tullius SG, Pratschke J. Novel markers in zero-hour kidney biopsies indicate graft quality and clinical outcome. Transplantation. 2010;90(9):958-65.

35. Gunther J, Resch T, Hackl H, Sattler A, Ebner S, Ritschl PV, Biebl M, Ollinger R, Schneeberger S, Brandacher $\mathrm{G}$, et al. Identification of the activating cytotoxicity receptor NKG2D as a senescence marker in zero-hour kidney biopsies is indicative for clinical outcome. Kidney Int. 2017;91(6):1447-63.

36. Sigdel TK, Bestard O, Tran TQ, Hsieh SC, Roedder S, Damm I, Vincenti F, Sarwal MM. A computational gene expression score for predicting immune injury in renal allografts. PLoS One. 2015;10(9):e0138133.

37. Meng H, Liang Y, Hao J, Lu J. Comparison of rejection-specific genes in peripheral blood and allograft biopsy from kidney transplant. Transplant Proc. 2018:50(1):115-23.

38. McArdel SL, Terhorst C, Sharpe AH. Roles of CD48 in regulating immunity and tolerance. Clin Immunol. 2016;164:10-20.

39. Qin L, Chavin KD, Lin J, Yagita H, Bromberg JS. Anti-CD2 receptor and antiCD2 ligand (CD48) antibodies synergize to prolong allograft survival. J Exp Med. 1994;179(1):341-6. 
40. Tchorsh-Yutsis D, Hecht G, Aronovich A, Shezen E, Klionsky Y, Rosen C, Bitcover R, Eventov-Friedman S, Katchman H, Cohen S, et al. Pig embryonic pancreatic tissue as a source for transplantation in diabetes: transient treatment with anti-LFA1, anti-CD48, and FTY720 enables longterm graft maintenance in mice with only mild ongoing immunosuppression. Diabetes. 2009;58(7):1585-94.

41. Yeap WH, Wong KL, Shimasaki N, Teo EC, Quek JK, Yong HX, Diong CP, Bertoletti A, Linn YC, Wong SC. CD16 is indispensable for antibody-dependent cellular cytotoxicity by human monocytes. Sci Rep. 2016;6:34310.

42. Matthias $P$, Rolink AG. Transcriptional networks in developing and mature $B$ cells. Nat Rev Immunol. 2005;5(6):497-508.

43. Chuang HC, Wang $X$, Tan TH. MAP 4K family kinases in immunity and inflammation. Adv Immunol. 2016;129:277-314.

44. Cosman D, Fanger N, Borges L, Kubin M, Chin W, Peterson L, Hsu ML. A novel immunoglobulin superfamily receptor for cellular and viral MHC class I molecules. Immunity. 1997;7(2):273-82.

45. Borges L, Hsu ML, Fanger N, Kubin M, Cosman D. A family of human lymphoid and myeloid Ig-like receptors, some of which bind to MHC class ! molecules. J Immunol. 1997;159(11):5192-6.

46. Shiroishi M, Kuroki K, Tsumoto K, Yokota A, Sasaki T, Amano K, Shimojima T, Shirakihara Y, Rasubala L, van der Merwe PA, et al. Entropically driven MHC class I recognition by human inhibitory receptor leukocyte lg-like receptor B1 (LILRB1/ILT2/CD85j). J Mol Biol. 2006;355(2):237-48.

47. Yu K, Davidson CL, Wojtowicz A, Lisboa L, Wang T, Airo AM, Villard J, Buratto J, Sandalova T, Achour A, et al. LILRB1 polymorphisms influence posttransplant HCMV susceptibility and ligand interactions. J Clin Invest. 2018;128(4):1523-37.

48. Schlondorff D, Nelson PJ, Luckow B, Banas B. Chemokines and renal disease. Kidney Int. 1997;51(3):610-21.

49. Jorgensen I, Miao EA. Pyroptotic cell death defends against intracellular pathogens. Immunol Rev. 2015;265(1):130-42.

50. Seeman T, Dusek J, Vondrak K, Spatenka J, Feber J. Profiling proteinuria in children after renal transplantation. Pediatr Nephrol. 2009;24(12):2439-44.

51. Yang SW, Choi JY, Kwon OJ. The impact of pretransplantation serum albumin levels on long-term renal graft outcomes. Transplant Proc. 2013; 45(4):1379-82.

52. Tancredi DJ, Butani L. Pretransplant serum albumin is an independent predictor of graft failure in pediatric renal transplant recipients. J Pediatr. 2014;164(3):602-6.

53. Trull A, Hughes V, Cooper D, Wilkins M, Gimson A, Friend P, Johnston A, Sharples L, Park G. Influence of albumin supplementation on tacrolimus and cyclosporine therapy early after liver transplantation. Liver Transpl. 2002;8(3): 224-32.

54. Li Y, Liu FY, Liu ZH, Huang YF, Li LS, Zhang X, Peng YM. Effect of tacrolimus and cyclosporine a on suppression of albumin secretion induced by inflammatory cytokines in cultured human hepatocytes. Inflamm Res. 2006; 55(5):216-20.

55. Zanger UM, Schwab M. Cytochrome P450 enzymes in drug metabolism: regulation of gene expression, enzyme activities, and impact of genetic variation. Pharmacol Ther. 2013;138(1):103-41.

56. Amundsen R, Asberg A, Ohm IK, Christensen H. Cyclosporine A- and tacrolimus-mediated inhibition of CYP3A4 and CYP3A5 in vitro. Drug Metab Dispos. 2012;40(4):655-61.

57. Klein K, Zanger UM. Pharmacogenomics of cytochrome P450 3A4: recent Progress toward the "missing heritability" problem. Front Genet. 2013:4:12.

58. Lehmann JM, McKee DD, Watson MA, Willson TM, Moore JT, Kliewer SA. The human orphan nuclear receptor PXR is activated by compounds that regulate CYP3A4 gene expression and cause drug interactions. J Clin Invest. 1998;102(5):1016-23.

59. Hirota T, leiri I, Takane H, Maegawa S, Hosokawa M, Kobayashi K, Chiba K, Nanba E, Oshimura M, Sato T, et al. Allelic expression imbalance of the human CYP3A4 gene and individual phenotypic status. Hum Mol Genet. 2004;13(23):2959-69.

60. Goodwin B, Hodgson E, D'Costa DJ, Robertson GR, Liddle C. Transcriptional regulation of the human CYP3A4 gene by the constitutive androstane receptor. Mol Pharmacol. 2002;62(2):359-65.
61. Torres Munoz A, Valdez-Ortiz R, Gonzalez-Parra C, Espinoza-Davila E, Morales-Buenrostro LE, Correa-Rotter R. Percutaneous renal biopsy of native kidneys: efficiency, safety and risk factors associated with major complications. Arch Med Sci. 2011;7(5):823-31.

\section{Publisher's Note}

Springer Nature remains neutral with regard to jurisdictional claims in published maps and institutional affiliations.
Ready to submit your research? Choose BMC and benefit from:

- fast, convenient online submission

- thorough peer review by experienced researchers in your field

- rapid publication on acceptance

- support for research data, including large and complex data types

- gold Open Access which fosters wider collaboration and increased citations

- maximum visibility for your research: over $100 \mathrm{M}$ website views per year

At $\mathrm{BMC}$, research is always in progress.

Learn more biomedcentral.com/submissions 